\title{
Perceptions of older people's oral health care among nurses working in geriatric home care
}

Taru Aro $^{\text {a }}$, Marjo Laitala ${ }^{\text {b }}$, Anna-Maija Syrjälä ${ }^{\text {c,d }}$, Marja-Liisa Laitala ${ }^{\text {a,e }}$, Jorma I. Virtanen ${ }^{\text {a,d }}$

${ }^{\text {a }}$ Research Unit of Oral Health Sciences, Faculty of Medicine, University of Oulu, 90014 Oulu, Finland

${ }^{\mathrm{b}}$ Social Sciences, Faculty of Education, University of Oulu, 90014 Oulu, Finland

${ }^{\mathrm{c}}$ Periodontology and Geriatric Dentistry, Research Unit of Oral Health Sciences, University of 90014 Oulu, Finland

${ }^{\mathrm{d}}$ Medical Research Center Oulu, Oulu University Hospital, Oulu, Finland

e Kallio Public Health Care, Ylivieska, Finland

Short title: Nurses' perceptions of old people's oral care

Correspondence:

Dr Anna-Maija Syrjälä

Unit of Oral Health Sciences Research

Faculty of Medicine, University of Oulu

FI-90014 Oulu, Finland

Finland

Tel.: +358

Fax: +35885375560

E-mail: anna-maija.syrjala@oulu.fi 


\section{ABSTRACT}

Objectives: This study investigates nurses' self-reported experiences and perceptions of older people's oral health care using a qualitative method.

Methods: We interviewed ten nurses working in geriatric home care who regularly visit and take care of older people in their homes. The interviews consisted of semi-structured questions. The interviews were then transcribed and analysed.

Results: All nurses were aware of the connection between oral health and general health, but more detailed knowledge about oral health was lacking and confidence in oral health care practices was limited. Many of the interviewees noted the cleaning of removable dentures and problems related to them, but did not mention anything about periodontal diseases. Oral health education among the nurses was rare. The nurses reported lack of time to take care of their clients' oral health. As possible development steps, the interviewees suggested that including oral health care in the daily treatment plan would improve oral health care practices.

Conclusions: The nurses' lack of knowledge about oral health care and uncertainty in oral health practices among older people are major problems in daily geriatric home care. Oral health education and confidence in oral health practices should be improved in both basic and on-the-job education.

Key words: geriatric nurses, elder care, practice nursing, oral health care, qualitative study 


\section{INTRODUCTION}

Recent decades have seen a constant increase in life expectancy in industrialized countries. This increase has also been evident in the Nordic countries, and in Finland, for instance, the proportion of people aged 65 and older is nowadays about $18 \%$, and it is estimated to be $26 \%$ in 2030 [1]. In Finland, the aim is to enable older people to live at home for as long as possible. Today, about 72,000 older people in Finland benefit from regular services to enable them to live at home [2]. These older people are selected based on the international Resident Assessment Instrument (RAI) system, which serves as a benchmark for estimating older people's functional ability; home care is provided through public resources for those who need it [3]. Nurses working in geriatric home care help older people in their homes with oral selfcare practices and organize dental visits.

Today, most nursing curricula include either minimal oral health care or none at all. Nurses have been reported to face various barriers to ensuring the oral hygiene of their clients, such as a heavy work-load, lack of skills and knowledge concerning oral care, respect for older people's self-determination, and an inability to note their clients' oral status [4]. Furthermore, frail older people only complain about oral problems once they experience pain [5]. These factors may lead to a situation in which many asymptomatic problems related to oral health among older people - such as dental caries, periodontal problems, mucosal diseases, problems with chewing, problems with speech and bad breath - may be ignored. As a consequence of poor oral hygiene and dental care, older people may experience serious dental problems, decreased quality of life [6], nutritional problems [7], and increased morbidity [8]. The nursing staff should also be aware of the pressing need for preventive care [8]. 
In our previous report, we analysed various oral health-related beliefs and self-efficacy among nurses working in geriatric home care using a questionnaire [9]. We found that nurses mainly thought that oral diseases can be prevented and teeth can be retained during aging, but they had limited confidence in managing oral diseases.

The aim of this study was to investigate nurses' self-reported experiences and perceptions of older people's oral health care using a qualitative method. We examined the nurses' attitudes, knowledge, and views of oral health care among older people. This qualitative approach may help to target the oral health education needed to improve nurses' dental knowledge and confidence in daily oral health practices among older people.

\section{SUBJECTS AND METHODS}

This qualitative study among nurses working in geriatric home care and working in public health care and welfare services was carried out at Kallio Primary Care Services (KPCS) in central Finland. KPCS provides primary health care (including oral health care) and welfare services to a region that is home to 34,000 people, $19 \%$ of whom are aged 65 years or older. KPCS serves a typical, homogenous rural; the region includes two small towns in which the inhabitants have similar socio-economic and ethnic backgrounds. The main sources of livelihood in the region are services and small-scale industry. Geriatric home care is targeted at older people who rely on personal care that requires the professional expertise of social and health care staff; the aim is to ensure that the older people can live independent and high-quality lives in their own homes for as long as possible. The necessity for and right to home care provided through public resources is individually assessed using the international RAI-system. The nurse visits the client from once a week to several times a day as necessary; each visit 
involves nursing and home help, and can last from 15 minutes to two hours depending on the help required. KPCS provides home care services to 400-430 older people.

\section{Subjects}

As of May 2016, 140-150 nurses worked in geriatric home care for KPCS. The interview schedule was given to the head nurse, who informed the nurses about the interviews by e-mail. Voluntary nurses participated in the face-to-face interviews, which were continued until saturation of responses was reached. The interviewees contained both registered general nurses and assistant nurses. Registered general nurses have university of applied sciences education, while assistant nurses have vocational education. Altogether ten nurses participated in the interviews carried out by the first author (TA). The interviews took place in the office of KPCS's chief dental officer. Each interview took 20-30 minutes.

The interviews were based on the themes deduced from previous studies. Our previous study [9] showed that nurses working in geriatric home care had limited knowledge about oral health care of older people and expressed lack of confidence in their ability to manage oral diseases. This qualitative study aimed to deepen the understanding of the nurses' knowledge, skills and attitudes to oral health care of older people. An expert group consisting of university teachers, health services professional, and a sociologist evaluated the interview questions.

The interviews consisted of four themes. In addition to the background information (Table 1), we also surveyed nurses' oral health care education, perceived need for further education and their expectations regarding it. Nurses were asked how oral health care was included in their daily work among older people and what their routines were. They were also enquired about their thoughts of the importance of oral health towards general health and welfare of older 
people, and how to improve oral health care. The interviewees' own oral self-care habits were also asked. Our aspiration was to enable the nurses to tell about their experiences and attitudes as freely as possible in the interviews [10].

\section{Analyses}

The NVivo-program (NVivo 11 starter for Windows) was used to analyze the transcribed material. We used both deductive (concept-driven) and inductive (data-driven) content analysis, where the main categories are formed based on what is already known about the topic and the subcategories are based on the material [11]. When reading the material for the first time, it was condensed by eliminating issues that were not essential to the research question. The analysis began by selecting the unit of analysis [12]. Based on the target of the study the unit of analysis was determined as a sentence or whole thought. Next, the original utterances were removed from the material (phase 1 in Table 2) and reduced utterances were formulated (phase 2). Examples are shown in Table 2. Ten sub-categories were constructed by combining interconnected reduced utterances, and the sub-categories were combined into three general categories (phase 3 in Table 3): knowledge, work skills and development.

\section{Ethical consideration}

In this study, we followed the directives of the National Advisory Board on Research Ethics and we received study permission from KPCS. Participation was voluntary and informed consent was obtained from all individual participants included in the study. The data were collected and analysed without identifying the interviewees.

\section{RESULTS}


Three main themes emerged in our study, indicating the staff's expertise concerning factors related to knowledge, every day job skills, and development (Fig. 1).

\section{Older people's oral health care and the nursing staff's knowledge of it}

The importance of oral health to general health

All of the interviewees were aware of the importance of oral health to the general health of older people. The nurses working in geriatric home care seemed to know to some extent that oral inflammations are connected to general health, well-being, and quality of life, and they were aware of the impact of oral health on eating and thus. Some of the interviewees even noted that the appearance of the client's teeth has impact.

\section{Nurses' knowledge about oral health}

Based on the interviewees, the nurses' knowledge about oral health care has some gaps: "As personnel, we don't quite understand the importance of [oral care] from an overall point of view" (head nurse). One of the interviewees noted that at least concerning herself, her knowledge is quite superficial:

"I just know about thrush and if there is some pain or you see some root remnants or a tooth coming loose, then you know that there's an urgent need for dental care and a visit to the dentist must be arranged quickly. I am just not aware of oral changes, for example. If there were something [problems] in the mouth, I would not know [what to do]. Basic aphthous lesions and similar conditions I know. But I don't know if it is my business in that case or if the client should be transferred to another place" (assistant nurse since 2011).

\section{Education related to oral health}


The head nurse of the geriatric home care accepts the responsibility for ensuring that the nurses are adequately educated and that information is updated regarding the oral health care of older people: "If I think of my own role, it is my duty to ensure that it is possible to take part in [oral health] education and they [the nurses] can get the latest knowledge" (head nurse). Many years have passed since some of the employees had their nursing education, so some of their knowledge might be outdated, as one of the nurses who graduated in 2010 explained: "And then it's just that, although we've had it [training] in school, it's already been seven years since we went through it, and one forgets those things". In fact, it is not routine for oral health education to be included in the nursing curriculum.

The interviewees memories of the oral health care education they received during basic education were hazy, and the same was true of the further education they had received in the workplace. Many of the nurses acknowledged that they had not had any further oral health education at work, while one of the nurses stated that some education may have been organized: “We haven't had [any further education] at least, or I would have participated. There could have been something, but I haven't taken part" (assistant nurse since 2004). Another nurse noted: "We had [some further education] once in Nivala. There was the municipality's dentist. Some kind of bulletin-type [information], but not much" (assistant nurse since 2005). According to interviews, too little further education had been organized, and the education that had been organized was not attended by every nurse.

\section{Staff's work skills in changing everyday challenges}


Noticing oral health in the nurses' everyday work

Older people have various oral problems that are typically not reported to the nurses before they cause pain: such problems can be caused by dry mouth and candidiasis. The main problem seems to be poorly fitting prostheses and the diseases that result from them. Prostheses that are loose fitting abrade the mouth, so some of the older people take them out when eating. For this reason, nutritional intake is reduced when tougher foods, for example, are not eaten: "Many times this kind of dental problem means that we have to order puréed food" (registered nurse since 2006). Older people may avoid visiting the dentist for a long time. Many of the interviewees assumed that among those older people living at home, the dentist had not inspected their mouths for many years. In addition, some older people do not let nurses check their mouths. Nurses working in geriatric home care consider this a particular problem when older people have mental problems such as dementia:

'They [the clients] belong to a generation that didn't have access to or received dental care when they were younger and in working. One can see that [poor oral health] depends on previous poor [dental] care" (head nurse).

\section{Inclusion of oral health care in the daily treatment plan}

The interviews revealed that registering a daily oral health treatment plan into the patient information system particularly improves oral health care and helps in the daily oral self-care practices of clients. The oral health care of older people is focused on the evenings, when the schedule is easier. "We strive to see that teeth are taken care of at least once a day" (assistant nurse since 2013). The interviewees considered oral health care practices to be matter for the assistant nurses rather than the registered general nurses. Some of the clients need only be reminded and monitored regarding the management of their own oral self-care, while the nurse 
may need to clean a client's teeth or prostheses when elderly person is unable to do so him/herself.

\section{Management of the daily oral health care of older people}

Many of the nurses working in geriatric home care were uncertain of their own practices regarding oral health care. When asked how well they manage oral health care tasks, one of the assistant nurses with five years of experience in geriatric home care said that "I do feel that really we should have more [education]". There are reminders at the clients' homes that the prostheses have to be soaked once a week with a particular cleaning tablet. Many of the nurses stated that they take care of the clients' teeth in the same manner as they take care of their own or their children's teeth.

Nurses' resources for daily oral health care

When the nurses were asked about the resources for daily oral health care, they complained about a lack of time. Some of the nurses said that they had insufficient time for oral health care since the visits to the clients are so precisely scheduled. On the other hand, others highlighted that oral health care is part of basic care and toilet visits: “Well, tooth brushing doesn't take more than two minutes, so there's enough time. One can overlook something else." (assistant nurse since 2013).

\section{Nurses own oral self-care}

The majority of the interviewees stated that they take care of their own mouth, meaning cleaning their oral health regularly - although they did not specify what "regular cleaning" means. Many of the interviewees told having dental examination regularly. One of the interviewees stated: 
"I cannot begin or finish the day without tooth brushing. -It has an immediate effect on one's general condition if you have dirty teeth or an untreated mouth" (registered nurse since 2006).

\section{Development of expertise}

The interviewees agreed that (more) training is needed. Many noted that practical education is required, especially short refresher courses providing more information. The interviewees wanted to know more about general diseases and their impact on the mouth, "so that we would know what is normal and what to pay attention to" (assistant nurse since 2004).

\section{DISCUSSION}

To our knowledge, this was first qualitative study to investigate perceptions of the oral health care of older people among nurses working in geriatric home care. The nurses have some knowledge about oral health-related problems among older people, but they are uncertain of their own skills when performing oral health practices for older people. The results of this study are in line with our previous study, which showed that nurses have limited oral health care knowledge about how to prevent dental diseases [9].

The association between oral health and general health was rather well known, but more detailed knowledge about oral diseases was lacking. The nurses did not mention periodontal problems, which are a major cause of issues for older people [13]. Furthermore, there is scientific evidence about the relationship between periodontal disease and systemic diseases such as diabetes [14]. On the other hand, the association between masticatory function and 
nutrition was particularly well reported by the interviewed nurses. Overall, more detailed knowledge about oral health is missing.

The interviewed nurses concluded that older people do not report dental problems until they cause pain. According to our interviewees, most of the older people living at home have not visited a dentist for many years. Surprisingly, the nurses did not mention relatives when asking about older people's oral health care. The nurses play a major role in organizing dental visits when the relatives of older people do not. However, it is often unclear whether the responsibility for this rests with the nurses working in geriatric home care or the client's relatives. It has also been noted that most older people are unwilling to leave their homes. In this situation, and when cognition and daily functioning decrease, home visits by a dentist would be optimal [15].

The nurses reported that they have limited time during home visits and their work is strictly scheduled. However, oral health practices were conducted in the evenings, when more time is available. It seems that a lack of time as the main reason for neglecting oral health practices is relative; some nurses noted insufficient time while others considered the client's oral health care so important that they did not mind having to hurry. Registering a daily oral health treatment plan into the patient information system seems to improve daily oral health care during home visits. Nihtilä et al. (2017) reported similar results [16]. When oral hygiene is registered into the daily treatment plan, the nurses make time for it.

Many dental problems could be prevented by careful oral home care, but most of the nurses are uncertain about oral health practices and their self-efficacy is poor, which is same result we found in our previous study [9]. In addition, dental hygienists have been found to be willing to offer treatment, but their self-perceived competency was insufficient to carry out such measures 
[17]. Nurses often have limited training and knowledge about older people's oral treatment needs [18-20]. In our study, earlier oral health education was forgotten and on-the-job training was scarce. The interviewees agreed that if they had more oral health education, they would practice better oral health care and denture hygiene. Only one of the interviewees mentioned receiving a good education concerning oral health.

It has been shown that oral health care education for nurses improves the oral health and denture hygiene of older people with and without dementia [21]. In Finland, oral health education is not systematically included in nursing curricula. Oral health education should be intensified in both professional nursing education and on-the-job training. Furthermore, the interviews revealed that the head nurse plays an important role when organizing oral health education to ensure they receive the latest knowledge about oral health.

The study's strengths include the homogenous target population and the interviewees' willingness to participate in the study and to express their perceptions. We interviewed ten persons with various levels of work experience and education. The answers were saturated with this number of interviewees, which confirms that the insight of the interviews was sufficient for the study's purposes. According to the instrumental utility of the interviews, we uncovered new perceptions of oral health care among nurses working in geriatric home care that help to identify the dental education needed. The coherence of the study was shown by the interviews confirming our previous study [9]. However, it must be kept in mind that the nurses might have had a tendency to provide socially desirable answers which is especially seen in face-to-face interviews and among females [22]. This could have influenced the responses. 


\section{Conclusions}

This qualitative study confirms our previous results: the nurses had limited confidence in their abilities to manage oral diseases. Using a qualitative approach, we were able to achieve a deeper understanding of what is needed to improve the situation. Oral health education - including information about daily oral care practices, periodontal infection, and the association between oral health and general health - is needed, and practical training in daily oral care practices should be organized. These aspects of education should be included both in basic nursing and on-the-job education. Furthermore, registering a daily oral health treatment plan into patient information system would improve oral health care practices. Those in charge have a great responsibility for ensuring adequate on-the-job oral health education for nursing staff.

It can be concluded that the nurses' lacking knowledge about oral health care and uncertainty in oral health practices among older people are major problems in daily geriatric home care. Oral health education and confidence in oral health practices should be improved both in basic nursing and on-the-job education. 


\section{REFERENCES}

[1] Official Statistics of Finland, 2012. Statistics Finland. http://www.stat.fi/til/vaenn/2012/vaenn 2012 2012-09-28 tau 001 fi.html. (Last accessed 25.10.2017)

2. National Institute for Health and Welfare (THL). http://www.thl.fi/fi/tilastot/tilastotaiheittain/ikaantyneiden-sosiaalipalvelut/kotihoidon-laskenta. (Last accessed 25.10.2017)

3. Hirdes JP, Ljunggren G, Morris JN, Frijters DH, Finne Soveri H, Gray L, et al. Reliability of the interRAI suite of assessment instruments: a 12-country study of an integrated health information system. BMC Health Serv Res. 2008;8:277.

4. De Visschere L, de Baat C, De Meyer L, van der Putten G-J, Peeters B, Söderfelt B, et al. The integration of oral health care into day-to-day care in nursing homes: the qualitative study. Gerodontology 2015;32:115-122.

5. Wårdh I, Berggren U, Andersson L, Sörensen S. Assesment of oral health care in dependent older persons in nursing facilities. Acta Odontol Scand. 2002;60:330-336.

6. Petersen PE, Yamamoto T. Improving the oral health of older people: the approach of the WHO Global Oral Health Programme. Community Dent Oral Epidemiol. 2005;33:81-92.

7. Samnieng P, Ueno M, Shinada K, Zaitsu T, Wright FA, Kawagutchi Y. Oral health status and chewing ability is related to mini-nutritional assessment results in an older adult population in Thailand. J Nutr Gerontol Geriatr. 2011;30:291-304.

8. Komulainen K, Ylöstalo P, Syrjälä A-M, Ruoppi P, Knuuttila M, Sulkava R, et al. Determinants for preventive oral health care need among community-dwelling older people: A population-based study. Spec Care Dentist. 2014;34:19-26.

9. Pihlajamäki T, Syrjälä A-M, Laitala M-L, Pesonen P, Virtanen J.I. Oral health care-related beliefs among Finnish geriatric home care nurses. Int J Dent Hyg. 2016;14:289-294. 
10. Carter S, Henderson L. Approaches to qualitative data collection in social science. In Ebrahim, S. \& Bowling, A. (eds.) Handbook of Health Research Methods. Investigation, Measurement and Analysis. 2005 p.219-220.

11. Schreier M. Qualitative Content Analysis in Practice. Thousand Oaks (Calif.): Sage Publications. 2012:89-90.

12. Elo S, Kyngäs H. The qualitative content analysis process. J Adv Nurs. 2008;62:107-115. 13. Holmén A, Strömberg E, Hagman-Gustafsson ML, Wårdh I, Gabre P. Oral status in home-dwelling elderly dependent on moderate or substantial supportive care for daily living: prevalence of edentulous subjects, caries and periodontal disease. Gerodontology. 2012;29:e503-511.

14. Kandelman D, Petersen PE, Ueda H. Oral health, general health, and quality of life in older people. Spec Care Dentist. 2008;28:224-236.

15. Komulainen K, Ylöstalo P, Syrjälä A-M, Ruoppi P, Knuuttila M, Sulkava R, et al. Preference for dentist's home visits among older people. Community Dent Oral Epidemiol. 2012;40:89-95.

16. Nihtilä A, Tuuliainen E, Komulainen K, Autonen-Honkonen K, Nykänen I, Hartikainen S, et al. Preventive oral health intervention among old home care clients. Age Ageing. 2017;1-6. 17. Virtanen JI, Tseveenjav B, Wang NJ, Widström E. Nordic dental hygienists' willingness to perform new treatment measures: barriers and facilitators they encounter. Scand J Caring Sci. $2011 ; 25: 311-316$.

18. Gerritsen PFM, Schrijvers AJP, Cune MS, van der Bilt A, de Putter C. Assessment of the oral health condition of nursing home residents by primary care nurses. Spec Care Dentist. 2014;34:260-264.

19. Wårdh I, Jonsson M, Wikström M. Attitudes to and knowledge about oral health care among nursing home personnel--an area in need of improvement. Gerodontology. 2012;29:e787-92. 
20. Sjögren P, Kullberg E, Hoogstraate J, Johansson O, Herbst B, Forssell M. Evaluation of dental hygiene education for nursing home staff. J Adv Nurs. 2009;66:345-349.

21. Zenthöfer A, Meyer-Kühling I, Hufeland A-L, Schröder J, Cabrera T, Baumgart D, et al. Carers' education improves oral health of older people suffering from dementia - results of an intervention study. Clin Interv Aging. 2016;11:1755-1762.

22. Hebert JR, Ma Y, Clemow L, Ockene IS, Saperia G, Stanek E J, et al. Gender differences in social desirability and social approval bias in dietary self-report. Am J Epidemiol. 1997;146:1046-1055. 
Figure legend

Figure 1. Three main themes emerged in our study; factors related to knowledge, every day job skills, and development 
Table 1. Interviewees' background (graduation, working experience and education).

\begin{tabular}{lll}
\hline & & $\mathbf{n}$ \\
\hline \multirow{2}{*}{ Time from graduation (years) } & $<5$ & 2 \\
\cline { 2 - 3 } & $5-10$ & 3 \\
\cline { 2 - 3 } & $>10$ & 5 \\
\hline Working experience at & $\leq 5$ & 4 \\
\cline { 2 - 3 } geriatric home care (years) & $6-14$ & 2 \\
\cline { 2 - 3 } & $\geq 15$ & 4 \\
\hline Education & Registered general nurse & 3 \\
\cline { 2 - 3 } & Assistant nurse & 7 \\
\hline
\end{tabular}


Table 2. Analysing phase 1 and 2, example (original utterances, reduced utterances and subcategories).

\begin{tabular}{|l|c|c|}
\hline Utterance & Reduced utterances & Sub-category \\
\hline $\begin{array}{l}\text {..Even if I do or say } \\
\text { anything, they do } \\
\text { according to their } \\
\text { own mind. } \\
\text { (registered general } \\
\text { nurse 1998) }\end{array}$ & Self-will & \\
.. When they are all \\
living at home, they \\
$\begin{array}{l}\text { are quite independent. } \\
\text { (assistant nurse 2001) }\end{array}$ & Independence & Clients' self-care \\
$\begin{array}{l}\text {..They want } \\
\text { themselves to take } \\
\text { care. So it isn't } \\
\text { obvious that we are } \\
\text { brushing their teeth. } \\
\text { (registered general } \\
\text { nurse 2006) }\end{array}$ & \\
\end{tabular}


Table 3. Analyzing phase 3, example (sub-categories and main category).

\begin{tabular}{|l|l|}
\hline Sub-categories & Main category \\
\hline Clients' own self-care & \multirow{2}{*}{ Knowledge } \\
\cline { 1 - 1 } Knowledge about oral health & \\
\cline { 1 - 1 } Importance of oral health & \\
\hline Oral health care education & \\
\hline
\end{tabular}

